\title{
A generic tool for cost estimating in aircraft design
}

\author{
S. Castagne $\cdot$ R. Curran $\cdot$ A. Rothwell $\cdot$ M. Price $\cdot$ \\ E. Benard $\cdot S$. Raghunathan
}

Received: 6 September 2005 / Accepted: 3 September 2007/Published online: 8 January 2008

(C) Springer-Verlag London Limited 2008

\begin{abstract}
A methodology to estimate the cost implications of design decisions by integrating cost as a design parameter at an early design stage is presented. The model is developed on a hierarchical basis, the manufacturing cost of aircraft fuselage panels being analysed in this paper. The manufacturing cost modelling is original and relies on a genetic-causal method where the drivers of each element of cost are identified relative to the process capability. The cost model is then extended to life cycle costing by computing the Direct Operating Cost as a function of acquisition cost and fuel burn, and coupled with a semiempirical numerical analysis using Engineering Sciences Data Unit reference data to model the structural integrity of the fuselage shell with regard to material failure and various modes of buckling. The main finding of the paper is that the traditional minimum weight condition is a dated and sub-optimal approach to airframe structural design.
\end{abstract}

S. Castagne $\cdot$ R. Curran - M. Price $\cdot$ E. Benard .

S. Raghunathan

Center of Excellence for Integrated Aircraft Technology,

School of Aeronautical Engineering, Queen's University Belfast,

Ashby Building, Belfast BT9 5AG, UK

e-mail: r.curran@qub.ac.uk

A. Rothwell

Faculty of Aerospace Engineering,

Delft University of Technology,

PO Box 5058, 2600 GB Delft, The Netherlands

Present Address:

S. Castagne $(\square)$

SIMTech (Singapore Institute of Manufacturing Technology),

71 Nanyang Drive, Singapore 638075, Singapore

e-mail: sylviec@SIMTech.a-star.edu.sg
Keywords Cost modelling - Manufacturing cost . Life cycle cost $\cdot$ Airframe design · Optimisation

\section{List of symbols}

$A_{i} \quad$ cross section area of the part $i$

$b \quad$ stringer pitch

$b_{\text {red }} \quad$ width of the chemi-milled pockets

$C_{i}^{m, f \text { or } a}$ material, fabrication or assembly cost for the cost element $i$

$c_{i}^{m, f \text { or } a}$ material, fabrication or assembly cost coefficient for the cost element $i$

E Young's modulus

$F \quad$ chemi-milling correction factor for the local buckling coefficient

$G_{i}^{m} \quad$ material cost function for the cost element $i$

$k \quad$ radius of gyration

$K_{\mathrm{F}} \quad$ flexural buckling coefficient

$K_{\mathrm{L}} \quad$ local buckling coefficient

$K_{\mathrm{R}} \quad$ rivet buckling coefficient

$K_{\mathrm{S}} \quad$ shear buckling coefficient

$H \quad$ stringer height to stringer pitch ratio

$h \quad$ stringer height

$L_{\mathrm{F}} \quad$ frame pitch

$L_{i} \quad$ length of the part $i$

$n \quad$ weight factor for DOC computation

$n_{i} \quad$ number of parts of type $i$

$p \quad$ loading intensity

$p_{\text {pockets }}$ total perimeter of the chemi-milled pockets

$q \quad$ shear flow

$r_{i}^{f \text { or } a}$ fabrication or assembly rate coefficient for the cost element $i$

$r_{\mathrm{p}} \quad$ rivet pitch

$T$ ratio of stringer thickness to thickness of the chemi-milled pockets

$t_{0} \quad$ initial skin thickness 


\begin{tabular}{|c|c|}
\hline$t_{\mathrm{b}}$ & skin thickness of the panel with no chemi-milling \\
\hline$t_{\text {red }}$ & thickness of the pockets after chemi-milling \\
\hline$t_{\text {removed }}$ & thickness removed by chemi-milling \\
\hline$t_{\mathrm{s}}$ & stringer thickness \\
\hline$t_{\text {sheet }}$ & sheet thickness \\
\hline$u_{i}^{f \text { or } a}$ & $\begin{array}{l}\text { fabrication or assembly utilizationfactor for th } \\
\text { element } i\end{array}$ \\
\hline$W$ & weight of the panel \\
\hline$\sigma$ & applied compressive stress \\
\hline$\sigma_{\mathrm{F}}$ & flexural buckling stress \\
\hline$\sigma_{\mathrm{L}}$ & local buckling stress \\
\hline$\sigma_{\mathrm{VM}}$ & von Mises equivalent stress \\
\hline$\tau$ & applied shear stress \\
\hline$\tau_{\mathrm{B}}$ & buckling stress in pure shear \\
\hline
\end{tabular}

\section{Introduction}

As the design influences between 70 and $85 \%$ of the total life cycle cost (LCC), i.e. cost of developing, producing, using and retiring a product, designers are in a position to substantially reduce it (Asiedu and $\mathrm{Gu}$ 1998). There is therefore a need to develop methodologies to estimate the cost implications at the early design stage.

Three different cost estimating methods are usually identified: analogous, parametric and detailed. Analogous models estimate the cost by analogy with an existing similar product. This method requires an expert judgment and a complete familiarity with the product but is very good for new products (Asiedu and Gu 1998). Parametric cost analysis is a mathematical approach to cost analysis that uses non-cost parameters to estimate the cost to bring forth, sustain and retire a product. It consists in the development and application of equations or cost estimation relationships (CERs) that describe relationships between cost, schedule and measurable attributes of systems (Dean 1995). This method has also been applied to estimate the cost of the design process itself (Roy 1999). Considerable effort is involved in the collection of data and generation of equations but when the CERs are available, estimates can be produced rapidly. Nevertheless, this method is not very good for product utilizing new technologies. Finally, the detailed method consists in estimating the direct costs of a product or activity using estimates of labour times and rates, material quantities and prices. This method, which gives the most accurate estimates, is the most time consuming and costly approach and it requires very detailed knowledge of the product. Activity-based costing (ABC) is a detailed method, which evaluates the cost of a product from a decomposition of the work required into elementary tasks, operations or activities. Usually used as part of total cost management, this method has also been successfully used at the design stage for prediction purpose (Pantelakis and Baxevani 2002; Ben-Arieh and Qian 2003; Feng and Song 2003).

Research work on product acquisition cost, as part of the LCC, is abundant in literature. In this context, multidisciplinary design optimisation (MDO) models no longer focus only on optimising aerodynamic performance or minimizing structural weight, but are now turning towards other objectives such as minimizing manufacturing cost (Kassapoglou 1999; Bao and Samareh 2000; Wang et al. 2002; Rigo 2003).

The impact of design on direct operating cost (DOC) is also documented in the literature. For example, in the field of aeronautics, works concerning analyses of the return of investment of the airline in relation with the variation in the acquisition cost due to a design modification (Marx et al. 1995), analyses of the influence of manufacturing tolerance on aircraft DOC (Curran et al. 2003) or parametric studies to understand the impacts of new technologies on development, production, operation and support costs (Collopy and Horton 2002) can be cited.

Unifying the design tools for optimisation across multiple analytical disciplines is very important. In this context, generic frameworks for cost estimation in product design have been developed (Weustink et al. 2000; Koonce et al. 2003). Generally, to produce an estimate, a work breakdown structure (WBS) tree of the product is built and the manufacturing cost is computed according to the information related to each cost element. Appropriate estimation methods and cost relationships are chosen depending on the information available at each particular design stage.

However, there has been very little published work in the linkage and simulation of accurate cost estimation and detailed structural requirements. Consequently, the present paper describes initial findings of a research study on the integration of cost estimating into the aircraft design process. The aim of the project is to develop a generic methodology for total cost modelling that will facilitate the design integration of the aircraft as a complete system. The cost model is developed on a hierarchical basis, focusing first on the manufacturing cost analysis of representative fuselage panels. The model can be subsequently extended in two major directions by including operation and maintenance costs to predict the total LCC and/or by adding other subsystems to finally analyse the cost of the entire aircraft. Within this framework, the implications of any change in the system definition are directly reflected on the cost. Therefore, the model has to give realistic estimates of the effects of design and process changes. By coupling the cost analysis with a structural analysis, it is then possible to optimise the panel 
not only for weight, which is the common practice in aircraft design, but also for cost.

\section{Development of the manufacturing cost model}

The manufacturing cost model is developed using the genetic-causal method as described by Curran et al. (2006), where each cost element is computed in relation to its main cost drivers, these being linked to particular genetic identifiers relating to materials, processes and forms. The cost elements can be anything that incurs a cost such as a part or an assembly operation. The objective is to define averaged cost equations that depend on the design parameters and that do not require detailed analyses at each manufacturing step. The model can be viewed at different levels of aggregation, from raw material to parts and assemblies. The idea is to follow the material transformation route from its beginning, with the advantage that the cost of bought or semi-manufactured parts can be integrated at the appropriate aggregation level. The methodology implies that the system has to be divided into different part families for which specific cost equations can be developed. For each parts family, the manufacturing cost is decomposed into three components: material cost, fabrication cost and assembly cost. As the cost model is to be coupled with a structural model, these two analysis disciplines have to use the same design variables.

Data have been collected in the form of bills of material, engineering drawings and engineering process records for the panels that comprise the main fuselage of a regional passenger jet. Using regression analyses, cost equations are determined from these data for each parts family. The statistical significance is poor for some of the equations but it can be improved when more data will be available. The generic part families appearing in a typical stringer-skin panel are the panel itself, which forms the skin of the aircraft, the stringers and the frames that support it in the longitudinal and lateral directions, and the shear cleats that are present at the stringer-frame junctions.

Generic equations for the material cost (Eq. 1), fabrication cost (Eq. 2) and assembly cost (Eq. 3) are given hereafter; the exponent $m$ refers to material, $f$ to fabrication and $a$ to assembly. Square brackets are used to specify the dimensions of the different variables in the equations. It is worth noting that the fabrication costs only include the inhouse labour costs. This means that for several parts, the material costs also include fabrication costs. For example, relative to the particular industrial data available, the material cost for the skin panel already includes the cost of rolling. Likewise, the stringers' material cost already includes the cost of the extrusion process. The rivets are standard commercial parts, which are received in their manufactured state. From a costing point of view, the rivets are part of the material costs.

$$
\begin{aligned}
C_{i}^{m}[\text { unit currency }]= & G_{i}^{m}\left(L_{i}, A_{i}, \ldots\right) \\
& \cdot c_{i}^{m}\left[\text { unit currency } / \mathrm{mm}, \mathrm{mm}^{2}, \ldots\right]
\end{aligned}
$$

$C_{i}^{f}[$ unit currency $]=r_{i}^{f}[$ unit currency/unit time $] \cdot u_{i}^{f}$ - $c_{i}^{f}[$ unit time $]$

$C_{i}^{a}[$ unit currency $]=r_{i}^{a}[$ unit currency $/$ unit time $] \cdot u_{i}^{a}$ - $c_{i}^{a}[$ unit time $]$

In Eq. (1), the dimension of the material cost coefficient $c_{i}^{m}$ changes according the dimension of the material cost function $G_{i}^{m}$, which depends on various geometric variables according to the part concerned, as exemplified later in this paper.

The most efficient way to measure a labour cost is to use a standard labour time $c_{i}^{f}$ or $a$, which can then be multiplied by an utilization factor $u_{i}^{f}$ or $a$ and a rate (cost/unit time) $r_{i}^{f}$ or $a$ to obtain the final cost as illustrated by Eqs. (2) and (3). Rates and utilization factors are very important parameters of the cost model but they are also very difficult to estimate. Rates are highly linked to the process. They usually include labour cost but also part of tooling cost, consumables and overheads. The standard time is the time to make a part in theory but it takes longer in reality. Therefore, utilization factors account for the actual period during which the tools have to be considered to be used, they include such things as learning curves, breaks, etc. Utilization factors are determined by the company efficiency.

The cost coefficients $c_{i}^{m}, c_{i}^{f}$ and $c_{i}^{a}$, which appear in Eqs. (1-3), are detailed in the following sections. For proprietary reason, the costing equations have been scaled. No particular currency is given but the unit of cost is chosen to be the cost of one representative rivet. Concerning the labour time, the unit time is the autoriveter time to place one rivet.

\subsection{Material cost}

Ideally, the material cost should be the cost of the raw material before any transformation but according to the industrial data available the model has been built using the term "material cost" for the cost of the material as bought by the factory. This means that the material may have already been transformed. For example, the material cost for the stringers is the cost of extruded aluminium while the material cost for the cleats is the cost of a piece of metal sheet. Therefore labour and energy have been expended and are included. 
Three categories of raw material are analysed: skin sheet (thickness $\geq 2.5 \mathrm{~mm}$ ); sheets (thickness $<2.5 \mathrm{~mm}$ ) used to make frames, cleats and other reinforcing parts; extrusions used to make the stringers. According to the definition commonly used (ASM 1990), all our aluminium flat products are sheets (thickness between 0.15 and $6.25 \mathrm{~mm}$ ). Nevertheless, the decision to adopt the above criteria to separate skin and sheets was made for reasons of clarity because large skin sheets have a peculiar cost matrix which is not self evident. The skin cost is used for the skin itself. The sheet cost is used for the frames, cleats and other reinforcing parts. The extrusion cost is used for the stringers but can also be used for frames if extruded frames are preferred to sheet metal frames.

\subsubsection{Skin}

The material cost data collected for skin is shown in Fig. 1. This figure represents the cost by unit area as a function of the thickness. No logical relation can be found on this figure. After a discussion with the industrial partner and looking at the global matrix of data available there, it seems that no logical relation can be extracted even if a larger set of data is used. For confidentiality reasons, the whole set of data has not been provided. It was composed of a matrix giving the cost of aluminium plate per unit weight as a function of the thickness and width of the plate. This cost distribution is maintained by the supplier and is probably linked with commercial reasons. However it is found that different widths are associated with different process lines and each line is treated separately by the producers, the cost matrix reflecting the cost incurred for each line including spoiled runs, etc.

A logical cost distribution would be the following: cost per unit weight increases when the width of the plate increases as the tools needed for rolling become greater. Thinner plates become also more expensive per unit weight because they need more precision to make them and more

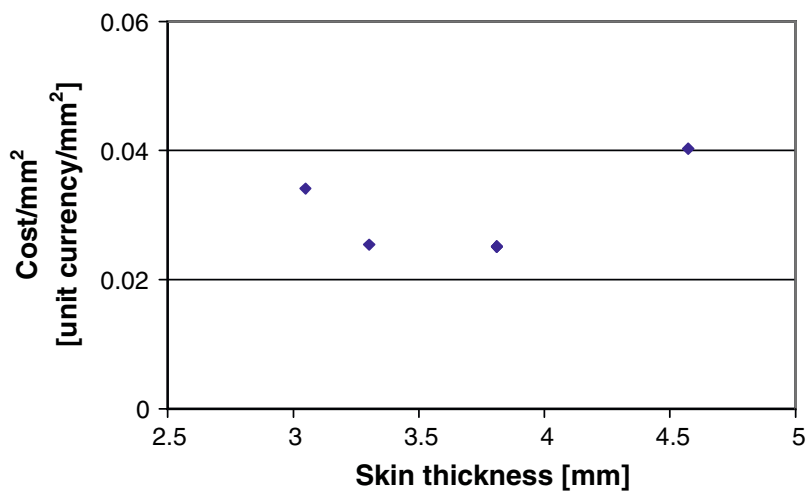

Fig. 1 Material cost for skin time. This evolution is not respected in the confidential cost matrix provided by the supplier, reinforcing the fact that the cost actually incurred and the price spent to purchase a product are to be differentiated. Cost and price are usually difficult to correlate as the later is a function of the market trends and commercial relationship between the buyer and supplier.

Following the above discussion and the difficulty in finding a coherent relation between the skin sheet dimension and its cost, it has been decided to introduce the data explicitly in the spreadsheet. The program determines the appropriate value according to the initial thickness of the plate before chemi-milling, the final thickness being obtained by this process. Indeed, only several plate thicknesses are usually available on the market and there is no need to find a relation covering a whole range of continuous thicknesses, still this represents a challenge to scientific cost modelling.

Practically, the amount of material to be taken into account corresponds to the final size of the panel at which 6 in. $(152.4 \mathrm{~mm})$ have been added to both width and length to allow for handling during chemi-milling.

\subsubsection{Sheets}

The material cost for sheets is presented in Fig. 2. By regression analysis, a linear characteristic that intercepts the cost axis at the origin has been fitted to the data. The data points on Fig. 2 cover four different aluminium tempers (2024-O, 2024-T3, 7075-O and 7075-T6). Nevertheless, a single linear equation is sufficient to represent the general sheet cost. This is confirmed by the $R$-squared value, which reveals how closely the estimated trend line is from the set of data, predicting $95 \%$ of accuracy.

Equation (4) gives the cost of one square millimetre of sheet as a function of its thickness; being a straight line passing through the origin, this is equivalent to a cost per unit volume or unit weight for sheet material.

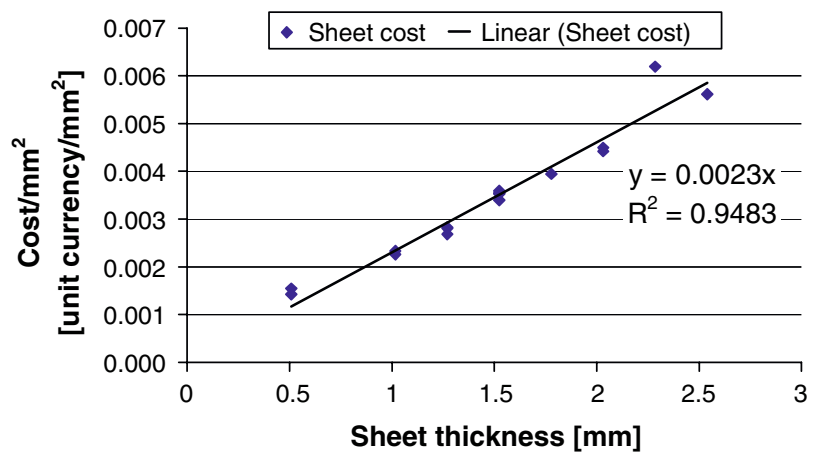

Fig. 2 Material cost for sheet 
$c_{\text {sheet }}^{m}\left[\right.$ unit currency $\left./ \mathrm{mm}^{2}\right]=2.303 \times 10^{-3} t_{\text {sheet }}[\mathrm{mm}]$

For each frame or cleat, the size of the sheet actually required corresponds to the envelop size of the deployed part plus an additional $15 \%$ area. The cost function $G_{\text {sheet }}^{m}$, appearing in Eq. (1) for a sheet metal part, is then the surface area of this envelop with an additional $15 \%$.

\subsubsection{Extrusions}

The cost driver for extrusion is the shape factor, which is defined as the ratio between the weight and the perimeter (ASM 1988): the higher this factor, the more complex the extrusion. This means that the extrusion rate is lower and that the cost of the dies is higher for a high shape factor, leading to an increase in the process cost.

Data were collected for all of the stringers used for the typical regional aircraft studied here. The majority are Zand T-stringers although L- and V-stringers are also used. The shape of the stringers was rather constant and there was not a lot of variation in their perimeter. Therefore it was not possible to find a relation between cost and the shape factor as expected. The only interesting relation that can be built with the available data is related to the weight of a unit length of extruded material, this means that the cost can be linked to the cross-sectional area of the stringer. For larger cross-sections, more material is needed to obtain one unit length of extruded material.

Figure 3 shows the material cost equations for the stringers. Two equations are proposed. Equation (5) is valid for T-stringers and includes L-stringers, both being made from 2024 aluminium alloy. Equation (6) is valid for Zand $\mathrm{V}$-stringers that are both made from 7075 aluminium alloy. The disparity is quite large for $\mathrm{V}$-stringers but they are not widely used, $\mathrm{V}$-stringers representing less than 5\% of the total usage.

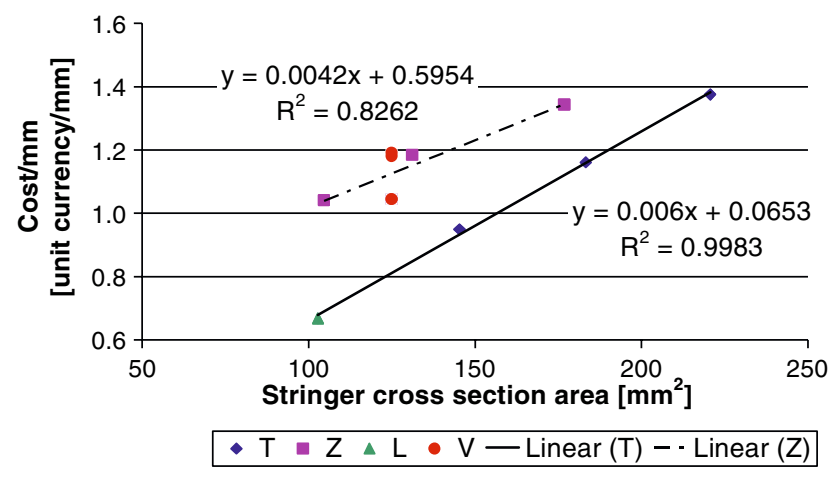

Fig. 3 Material cost for stringers

$$
\begin{aligned}
c_{T-\text { stringer }}^{m}[\text { unit currency } / \mathrm{mm}]= & 5.969 \times 10^{-3} A_{\text {stringer }}\left[\mathrm{mm}^{2}\right] \\
& +6.530 \times 10^{-2}
\end{aligned}
$$

$c_{Z \text {-stringer }}^{m}[$ unit currency $/ \mathrm{mm}]=4.238 \times 10^{-3} A_{\text {stringer }}\left[\mathrm{mm}^{2}\right]$

$$
+5.954 \times 10^{-1}
$$

The length of material to be considered for the costing and represented by the function $G_{i}^{m}$ in Eq. (1) corresponds to the length of the panel for a long stringer or to the frame pitch for an inter-window stringer; plus an excess amount of $15 \%$ in each case.

\subsubsection{Rivets}

The material cost for the rivets depends on the rivet's size and type (protruding head or countersunk). As the size of the rivets is not taken into account in the structural model, only an average cost is computed for each type of rivet. Protruding head rivets are used to rivet cleats to frames and stringers. Their cost has been chosen to be the reference cost in this paper and its value is 1 (unit currency/rivet). Countersunk rivets are used to rivet frames and stringers to skin. They are more expensive than the protruding head rivets, at a cost of 1.3 (unit currency/rivet). The number of rivets is computed by dividing the length of the part by the rivet pitch for frames and stringers. For the cleats, a fixed number of rivets per part is assumed.

\subsection{Fabrication cost}

The general expression for the fabrication cost is given by Eq. (2). The fabrication cost coefficients are presented in this section for each parts family. Rates and utilization factors reflect those provided by the industrial partner. The model is essentially based on labour hours so that the rates and utilization factors do not influence the results when times only are compared. Nevertheless, in order to compute the total cost and to perform the optimisation analysis, material, fabrication and assembly costs have to be summed, requiring assigned rates and utilization factors.

The fabrication cost is linked to the process, the initial shape of the material and to several features as detailed in the sections below for each parts family. It also includes treatments cost such as painting, anodizing, etc. in the present model.

\subsubsection{Skin}

The chemi-milling cost model is developed on the basis of the operations performed during the process. The chemi- 
milling cost is a function of the surface of the skin to be treated because it is related to the amount of maskant and etching product to be used, and to the cleaning time, etc. The second parameter is the perimeter of the pockets, which is proportional to the time needed to prepare the skin for chemi-milling. Finally, the number of chemi-milling steps and the amount of material to be removed at each step are also cost drivers; the first because it induces handling cost and the second, because it is linked to the chemimilling time and amount of etchant necessary.

For consistency with the rest of the cost model, the equations are written in equivalent standard times.

The process can be divided in two types of operations: the basic operations associated to the process and the actual process operations. Equation (7) concerns the basic operations and is composed of three terms. The first one stands for the application of the maskant, the second one for the scribing of the pattern and the third one for handling, cutting and stretching operations. Equation (8) is the equation for the process itself. The first term represents the handling cost, which is proportional to the number chemi-milling steps and to the surface area of the panel. The second term stands for the chemi-milling itself and depends on the total amount of material to be removed, and the third term concerns the final cleaning operations. The skin area that appears in all of the equations accounts for the excess amount of material needed for handling, except for the last term in which the final size of the panel is considered for cleaning.

$c_{\text {skin-basic }}^{f}[$ unit time $]=1.524 \times 10^{-4} A_{\text {skin }}\left[\mathrm{mm}^{2}\right]+3.261$

$$
\times 10^{-3} p_{\text {pockets }}[\mathrm{mm}]+56.4
$$

$c_{\text {skin-process }}^{f}[$ unit time]

$$
\begin{aligned}
= & \text { number of steps } \cdot 2.45210^{-5} A_{\text {skin }}\left[\mathrm{mm}^{2}\right] \\
& +9.464 \times 10^{-6} t_{\text {removed }}[\mathrm{mm}] \cdot A_{\text {skin }}\left[\mathrm{mm}^{2}\right] \\
& +1.087 \times 10^{-4} A_{\text {skin final }}\left[\mathrm{mm}^{2}\right]
\end{aligned}
$$

Finally, the total fabrication cost for the skin is given by multiplying the standard times by the appropriate rate and utilization factors as stated by Eq. (9), which derives from Eq. (2).

$C_{\text {skin }}^{f}[$ unit currency $]=r_{\text {skin }}^{f}[$ unit currency $/$ unit time $]$

$$
\begin{aligned}
& \cdot\left(u_{\text {skin-basic }}^{f} \cdot c_{\text {skin-basic }}^{f}[\text { unit time }]\right. \\
& \left.+u_{\text {skin-process }}^{f} \cdot c_{\text {skin-process }}^{f}[\text { unit time }]\right)
\end{aligned}
$$

\subsubsection{Stringers}

The fabrication cost for stringers is based on the length of the stringer. The independent term that appears in the model accounts for the work that has to be done to profile the ends of the stringers. Much machining work is done after extrusion but it cannot be represented in detail by the simple structural model, the equations proposed here are kept simple and tend to represent a mean stringer. Treatment operations such a cleaning and painting are also taken into account in these equations.

Two equations were identified: one for T-stringers (Eq. 10) and one for Z-stringers (Eq. 11) as illustrated in Figs. 4 and 5 . The length of the stringers in these equations reflects the $15 \%$ excess needed for machining.

$$
\begin{aligned}
c_{T-\text { stringer }}^{f}[\text { unit time }]= & 2.283 \times 10^{-2} L_{T-\text { stringer }}[\mathrm{mm}] \\
& +151.73 \\
c_{Z \text {-stringer }}^{f}[\text { unit time }]= & 1.008 \times 10^{-1} L_{Z-\text { stringer }}[\mathrm{mm}] \\
& +67.455
\end{aligned}
$$

\subsubsection{Frames}

The fabrication cost for frames is proportional to the number of lightening holes, which is proportional to the length of the frame in this model. Actually, machining

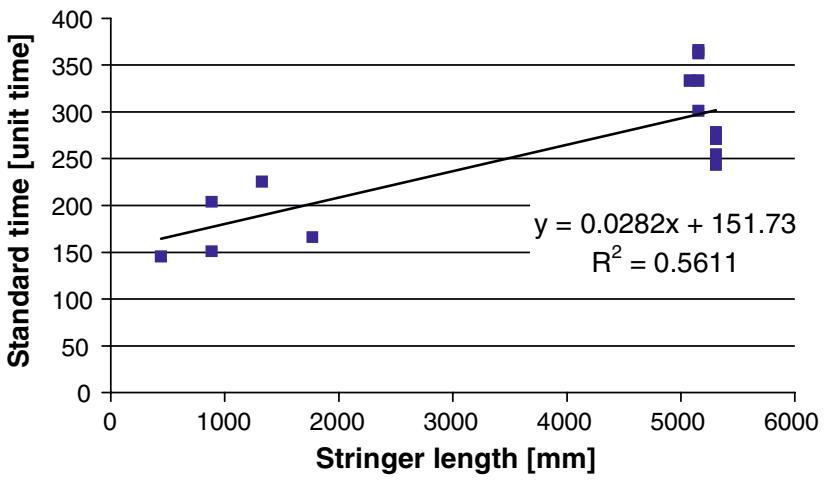

Fig. 4 Fabrication cost for T-stringers

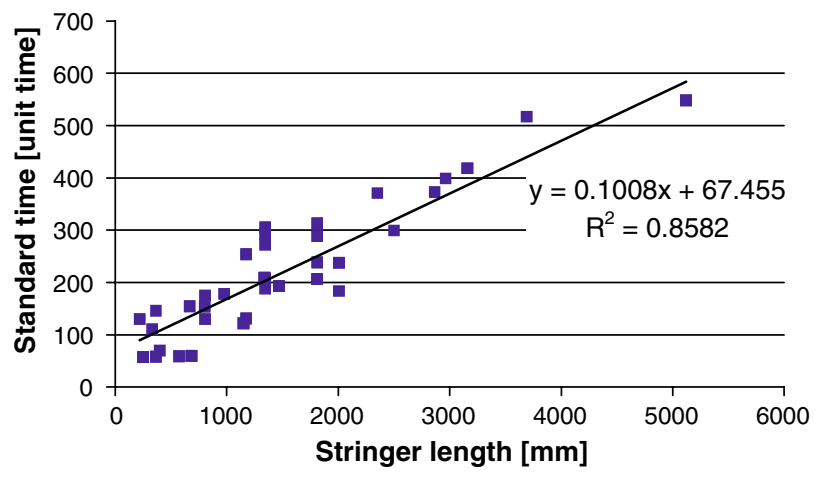

Fig. 5 Fabrication cost for Z-stringers 
work is also important for the frames but is not represented in the framework of the structure-cost optimisation process as the structural equations are not linked to these features. An additional cost driver could also be the number of stringers as a hole has to be machined for each stringer in the present configuration. This has not been taken into consideration yet.

All of the frames in the data set have the same length so the number that appears in Eq. (12) is simply an averaged value.

$c_{\text {frame }}^{f}[$ unit time $]=7.731 \times 10^{-1} L_{\text {frame }}[\mathrm{mm}]$

\subsubsection{Cleats}

A single type of shear cleat is used in the structural model and a single value for the cost of making cleats is considered (Eq. 13). Again a detailed model for machining and bending should give a reasonable cost for each form of cleat but this is not required in combination with the simple structural model.

$c_{\text {cleat }}^{f}[$ unit time $]=30$

\subsection{Assembly cost}

The assembly process considered here concerns riveting only but other assembly processes such as welding can be introduced in the general framework of the model for tradeoff purposes. In this paper, the assembly is based on the number of rivets to be introduced. Two phases are determined for the assembly process. The first phase, which is referred to as drilling and set up, includes drilling, dismantling, deburring and countersinking as well the time to prepare the parts and locate them together. The preparation time is included as an average: if the total number of rivets is higher, the total preparation time will be more important as well. At the same time, the number of rivets will be higher if the size of the parts increases, which is compatible with an increase in preparation time. The second phase is the riveting process itself.

The total number of rivets for a frame or a stringer is computed by dividing the length of the part by the rivet pitch. For T-stringers, the number of rivets has to be multiplied by two as there are two flanges to be riveted. For each cleat, four rivets have to be considered, two for riveting to the frame and two for riveting to the stringer.

\subsubsection{Manual riveting}

As explained, different operations are necessary for manual riveting. First the parts are put together and drilled. The drilling also includes operations such as dismantling, deburring or countersinking. The cost of these operations is higher for the cleats, as can be shown by comparing Figs. 6 and 7 . The parts are then riveted together. Figure 8 shows the results of the regression analysis for manual riveting. In this case, no difference is made between frames, stringers or cleats.

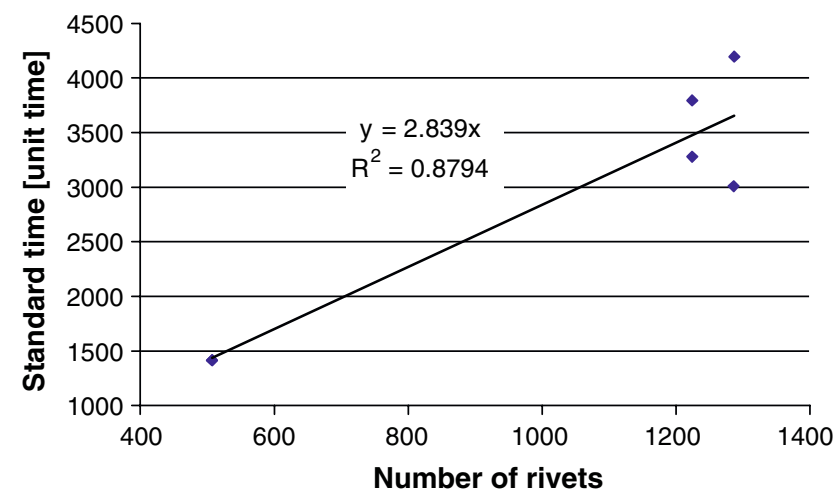

Fig. 6 Set up and drilling for frames and stringers

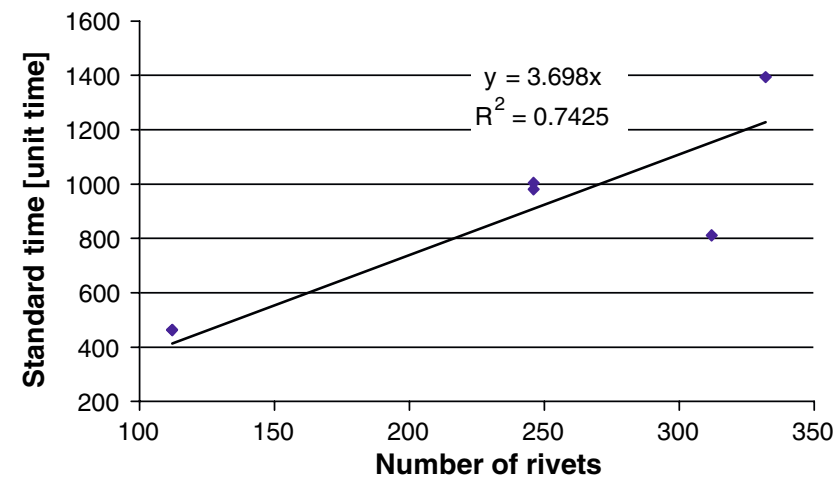

Fig. 7 Set up and drilling for cleats

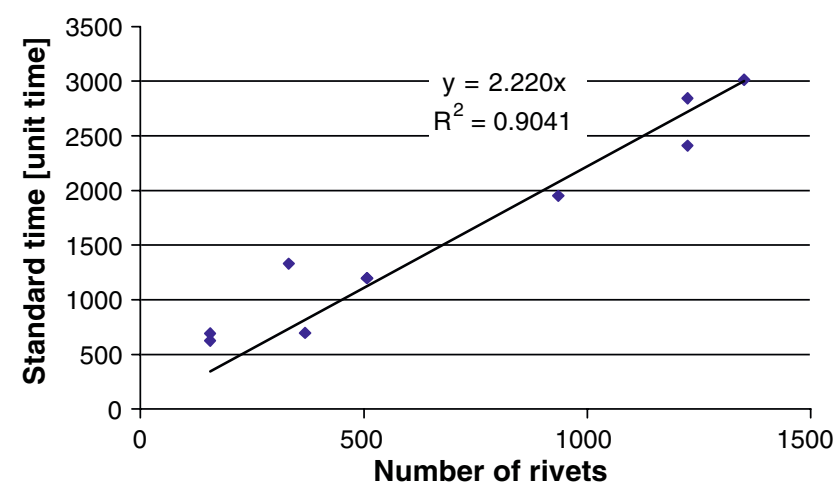

Fig. 8 Manual riveting for frames, stringers and cleats 
The cleats are always riveted manually. For the frames and stringers, it is supposed in this model than the rivets at their intersection are put manually as well as one or two rivets at mid-distance between two frames for Z-stringers or T-stringers, respectively.

The standard times to be introduced in an expression of the type of Eq. (3) for each manual assembly step are summarized by Eqs. (14-16).

$c_{\text {set up and drilling for frames or stringers }}^{a}$ [unit time]

$=2.839 \cdot n_{\text {holes for frames or stringers }}$

$c_{\text {set up and drilling for cleats }}^{a}[$ unit time $]=3.698 \cdot n_{\text {holes for cleats }}$

$c_{\text {manual riveting for frames, stringers or cleats }}^{a}$ [unit time]

$=2.220 \cdot n_{\text {rivets for frames, stringers or cleats }}$

\subsubsection{Automatic riveting}

For the automatic riveting, the machine drills, dismantles, deburrs, countersinks and rivets. The automatic riveting labour time has been chosen as a reference time for the model and is then equal to 1, as shown in Fig. 9 and Eq. (17).

$c_{\text {automatic riveting for frames or stringers }}^{a}[$ unit time]
$\quad=1.0 \cdot n_{\text {rivets for frames or stringers }}$

\subsection{Validation}

The model has been verified by estimating the cost of four of the panels (panels 1-4) that had been used to define the set of equations presented in this paper. To validate the model, two more panels (panels 5 and 6), which were not included in the first set of data, have been analysed. The rates and utilization factors used in the equations developed above are:

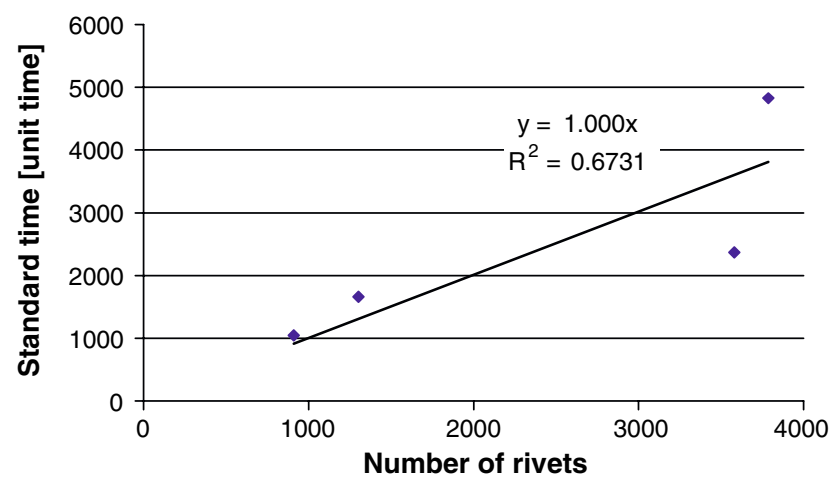

Fig. 9 Automatic riveting for frames and stringers $r_{\text {skin }}^{f}=29.5[$ unit currency/unit time]

$r_{\text {stringers, frames or cleats }}^{f}=35$ [unit currency/unit time],

$r_{\text {stringers, franes or cleats }}^{a}=24[$ unit currency/unit time],

$u_{\text {skin-basic }}^{f}=1.38, u_{\text {skin-process }}^{f}=1.13$,

$u_{\text {stringers, frames or cleats }}^{f}=1.45$ et $u_{\text {stringers, frames or cleats }}^{a}=1.18$.

Table 1 summarizes the characteristics of the different panels as well as the errors between the model estimations and the industrial data. The cutouts are either windows or doors. The cost of these parts are not computed by the model but it is important to take them into account to compute the actual length of the stringers as well as the number of stringers parts for one stringer location.

Two types of errors are computed for each panel: the global error, which is the error between the total estimated cost and the total actual cost, and the cumulative relative error, which is the sum of the absolute values of the relative error of each cost element. The second value reflects a more detailed analysis of the errors. Indeed, by computing a cumulative relative error, an underestimated value for a cost element is not balanced by an overestimate for another cost element, as it would be the case for the global error. The cost elements considered here are the same as in Figs. 10, 11, 12, 13, 14 and 15, i.e. the material and fabrication costs for each parts family and the material (rivets) and labour costs relating to the assembly. It can be concluded from Table 1 that the model gives relatively good estimates. The total cost is generally underestimated but the global error is never greater than $10 \%$ and the cumulative relative error remains less than $13 \%$ for every panel. It is worth noting that the errors for panels 5 and 6 , which were not included in the initial set of data, are also small and comparable to the errors for the other panels. These results are sufficiently good to validate the cost equations for these types of panels.

Figures 10, 11, 12, 13, 14 and 15 show the results of the model compared to the data for each cost element. The reference value is the total actual cost of the first panel which represents a cost of $100 \%$. All the other results have been scaled according to this value. The purpose of showing these graphs is to compare the estimates with the data and to identify the causes of error for each cost element. It is obvious from the graphs that the fabrication cost for the stringers is underestimated for most of the panels, except for panels 5 and 6 . The total assembly cost is also underestimated for the majority of them, except for panel 4 . These two cost elements are responsible for most of the error and could be better estimated with more detailed cost equations. For all the parts families, the material cost is smaller than the labour cost, except for the skin itself, and 
Table 1 Characteristics of the panels for validation

\begin{tabular}{lllllll}
\hline $\begin{array}{l}\text { Panel number } \\
\text { and type }\end{array}$ & $\begin{array}{l}\text { Panel size } \\
(\mathrm{m} \times \mathrm{m})\end{array}$ & $\begin{array}{l}\text { Number } \\
\text { of frames }\end{array}$ & $\begin{array}{l}\text { Number } \\
\text { of stringer } \\
\text { locations }\end{array}$ & $\begin{array}{l}\text { Number of } \\
\text { cutouts }\end{array}$ & $\begin{array}{l}\text { Global } \\
\text { error }(\%)\end{array}$ & $\begin{array}{l}\text { Cumulative } \\
\text { relative } \\
\text { error (\%) }\end{array}$ \\
\hline $1-\mathrm{T}$ & $4.9 \times 2.2$ & 12 & 13 & 0 & -0.47 & 4.98 \\
$2-\mathrm{T}$ & $4.7 \times 2.2$ & 6 & 13 & 0 & -9.46 & 12.78 \\
$3-\mathrm{Z}$ & $4.9 \times 2.2$ & 10 & 12 & 6 & -3.86 & 5.60 \\
$4-\mathrm{Z}$ & $4.7 \times 2.2$ & 5 & 12 & 6 & -1.30 & 12.55 \\
$5-\mathrm{T}$ & $3.3 \times 2.2$ & 8 & 13 & 0 & -2.15 & 6.10 \\
$6-\mathrm{Z}$ & $3.3 \times 2.2$ & 8 & 12 & 4 & -6.92 & 11.19 \\
\hline
\end{tabular}

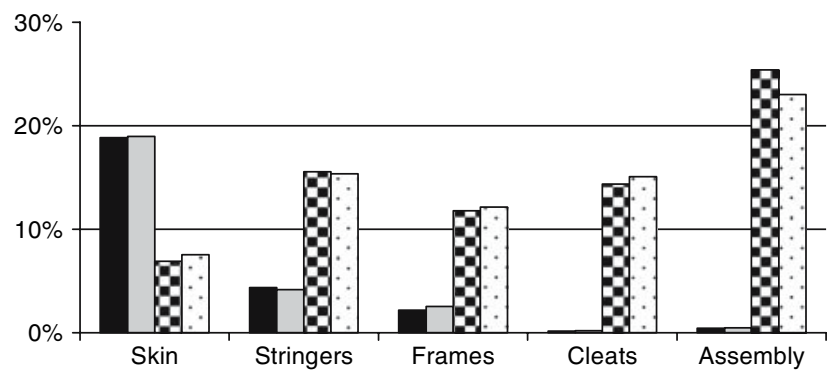

Actual Material $\square$ Estimation Material Actual Labour Estimation Labour

Fig. 10 Manufacturing cost for panel 1

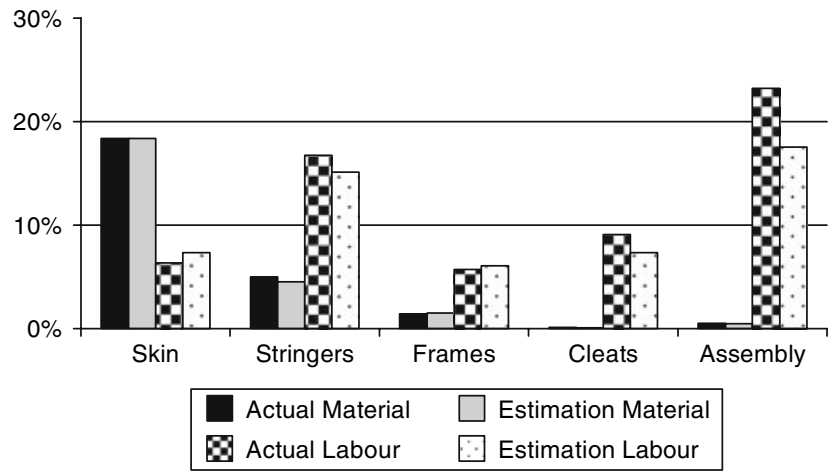

Fig. 11 Manufacturing cost for panel 2

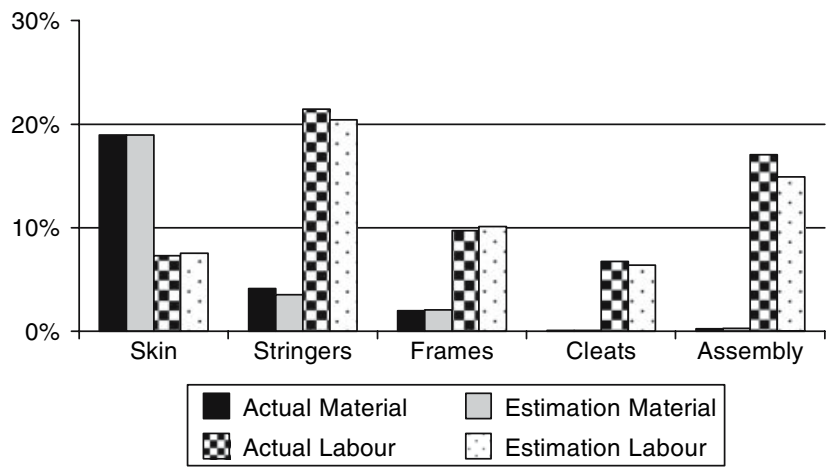

Fig. 12 Manufacturing cost for panel 3

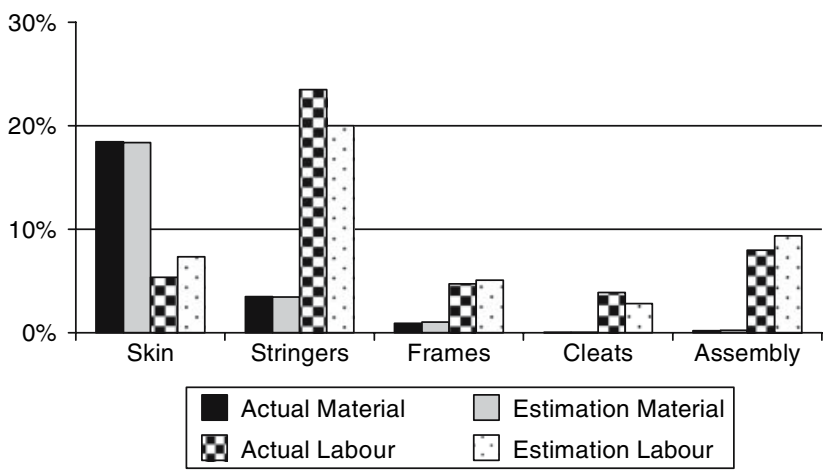

Fig. 13 Manufacturing cost for panel 4

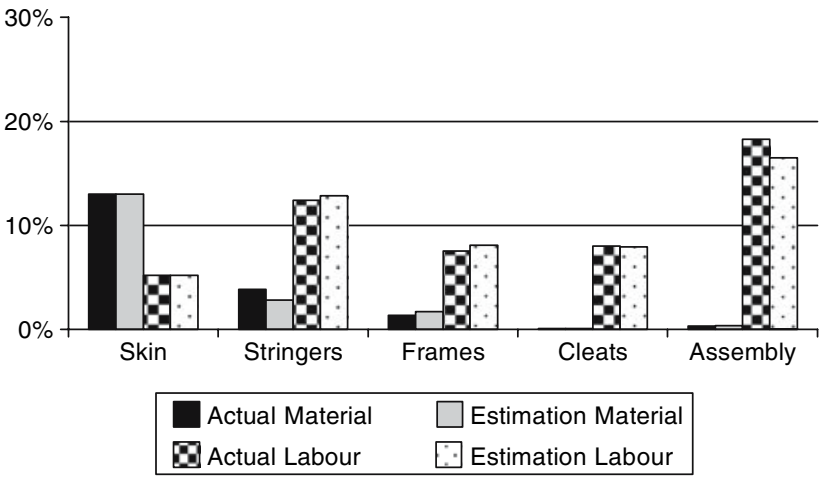

Fig. 14 Manufacturing cost for panel 5

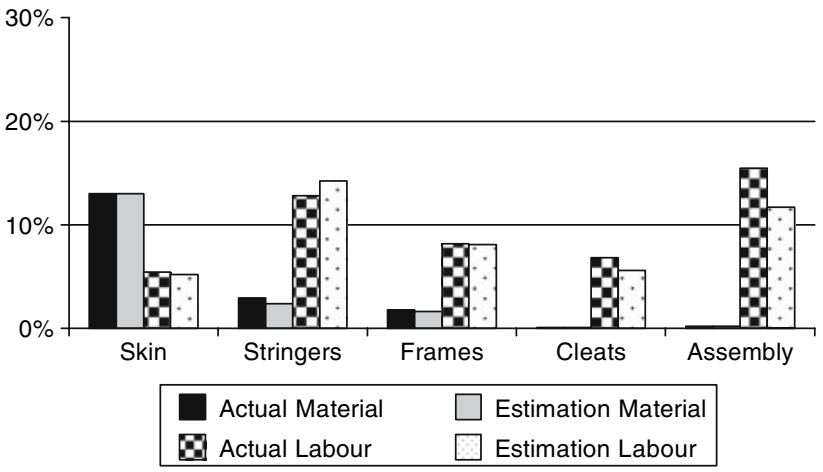

Fig. 15 Manufacturing cost for panel 6 
is usually well predicted. The fabrication cost for the frames is always overestimated while for the cleats both overestimates and underestimates appear according to the panel. Nevertheless, referring to Table 1 and to the comments made above, the total estimated cost is well predicted and the model is validated for the purpose of this research.

\subsection{Life cycle cost modelling}

The cost model can be extended to life cycle costing by computing the DOC that is associated with the cost of transporting a given weight of aircraft structure during the aircraft's life span. For commercial transport applications, the DOC is a function of the acquisition cost, fuel burn, maintenance, crew and navigation, and ground services. In particular, a detailed LCC analysis should also study the impact of factors such as damage, reparability, inspectability, robustness, etc. on the total cost.

As this work is concerned with linking and trading off structural efficiency with manufacturing cost, all DOC drivers can be said to be fixed apart from the acquisition cost and fuel burn, the neglected elements being said to be of much less importance to the structural airframe designer. Acquisition cost is driven by the cost of investing money to pay for the cost of the aircraft amortized unit manufacture, plus a profit margin, and can again be simplified and stripped of overheads and contingency to be a function of the cost of manufacture for design trade-off purposes. Fuel burn is a function of the specific fuel consumption and the cost of fuel and therefore can be said to be a function of weight in the current context.

The DOC function that is used for optimisation purposes later in this paper is summarized by Eq. (18). Although profit is a more obvious objective function, DOC can be more readily assessed as one form of an objective goal. It is composed of two terms: the acquisition cost (AC) and the fuel burn (FB), the acquisition cost being the manufacturing cost (MFC) multiplied by a weight factor $n$. For the majority of the flight sectors, the acquisition cost contributes two to four times more than the cost of fuel burn to the DOC. In keeping with the panel sizes addressed in the paper, it was shown that a $50 \%$ weighting for acquisition cost and $15 \%$ weighting for fuel burn is reasonable for the DOC split for an aircraft in the regional aircraft sector (Curran et al. 2006). Consequently, the factor $n$ was determined by fitting the cost results for a panel traditionally optimised for weight and the above mentioned percentage. The fuel burn was taken to be $300 \$ / \mathrm{kg}$ for this fitting, which is seen as a typical value. Finally, a value of $n=5$ was obtained.
$\mathrm{DOC}=\mathrm{FB}+\mathrm{AC}=\mathrm{FB}+n \cdot \mathrm{MFC}$

\subsection{Structural analysis}

The structural analysis is of a semi-empirical nature and utilizes various reference data from the Engineering Sciences Data Unit (ESDU) to predict the loads at which a given panel will fail. The structural analysis for inverted T-stringer panels has been described by Curran et al. (2006). The present paper focuses on Z-stringer panels with chemi-milled pockets. The equations are similar to those presented for T-stringer panels except that the buckling coefficients have to be adapted and that two different thicknesses have to be considered to account for the effect of chemi-milling. The panel modelled is shown in Fig. 16, where $b$ is the stringer pitch, $h$ the stringer height, $t_{0}$ the initial sheet thickness, $t_{\text {red }}$ the thickness of the pockets after chemi-milling and $t_{\mathrm{s}}$ the stringer thickness. It can be loaded under uniform compression with loading intensity $p$ combined with a uniform shear flow $q$. Failure modes considered are flexural buckling (long-wave), local buckling (short-wave), inter-rivet buckling (buckling of the skin between rivets), and material failure based on the allowable stress of the aluminium alloy material. Note that local buckling is not permitted, i.e. no post-buckled design is considered in the present study. Explicit formulae are derived for each of these modes, to facilitate their use in combination with cost formulae in a cost-weight optimisation process. Such formulae are inevitably an approximation to the real behaviour of the panel [as might be obtained, for example, by a full numerical analysis or Finite Element Analysis (FEA)] but are regarded as adequate at the current stage of the work. Furthermore, the intention is to develop a design tool which is both straightforward to use and readily programmed. Geometric constraints are applied in the subsequent optimisations to avoid unrealistic designs.

For flexural buckling the panel is assumed to be simplysupported at the frames, and wide enough so that there is no interference between adjacent stringers. Euler's formulae then gives for the flexural buckling stress $\sigma_{\mathrm{F}}$ :

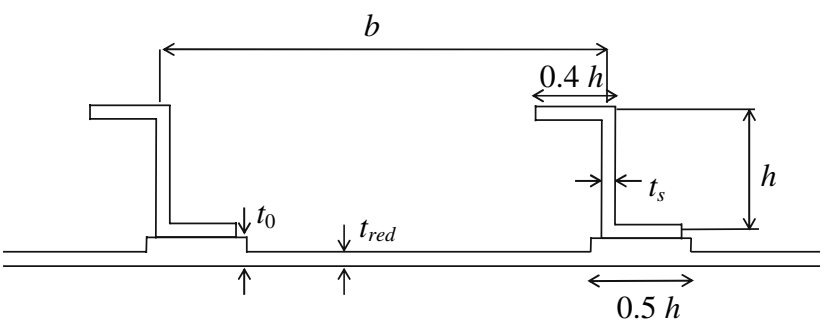

Fig. 16 Modelling of the Z-stringer panel for structural analysis 
$\sigma_{\mathrm{F}}=\frac{\pi^{2} E}{\left(L_{\mathrm{F}} / k\right)^{2}}$

where $E$ is the elastic modulus, $L_{\mathrm{F}}$ is the frame pitch and $k$ is the radius of gyration of the stringer with its attached skin. This formula is conveniently rewritten:

$\sigma_{\mathrm{F}}=K_{\mathrm{F}} E\left(\frac{b}{L_{\mathrm{F}}}\right)^{2}$

in which the flexural buckling coefficient $K_{\mathrm{F}}$ can be expressed as an explicit function of the shape ratios $h / b, t_{\text {red }} / t_{0}$ and $t_{\mathrm{s}} / t_{\text {red }}$.

Regarding local buckling, the buckling stress $\sigma_{\mathrm{L}}$ for a panel with no chemi-milling and with uniform skin thickness $t_{\mathrm{b}}$, is given by:

$\sigma_{\mathrm{L}}=K_{\mathrm{L}} E\left(\frac{t_{\mathrm{b}}}{\mathrm{b}}\right)^{2}$

Values of $K_{\mathrm{L}}$ are taken from data in the ESDU Structures Series (ESDU 1971b, Data Item 71014). This set of data takes into account the interaction between the stringer and the skin, which if omitted, would have led to some significant error. A polynomial approximation is used to represent the local buckling coefficient in the present analysis. A fourth-degree expression is found sufficient to give accuracy within $3 \%$ in the region of interest. For a Zstringer panel with a flange length equal to 0.4 the stringer height, as represented in Fig. 16, the expression is a function of the shape ratios $H=h / b$ and $T=t_{\mathrm{s}} / t_{\mathrm{b}}$ and is given by:

$$
\begin{aligned}
K_{\mathrm{L}}= & 4.2859-5.8779 H+0.6816 T \\
& +5.0983 H^{2}+3.4008 H T+0.8709 T^{2} \\
& -5.3247 H^{3}+2.1289 H^{2} T-1.5436 H T^{2} \\
& -0.2972 T^{3}
\end{aligned}
$$

To introduce the effect of chemi-milling, local buckling was calculated by means of the program in ESDU Data Item 98016 (ESDU 1998). This program is based on a finite strip method, enabling a chemi-milled pocket to be accurately modelled in the cross-section of the panel. The model also represents the rivets connecting the stringers. It was anticipated that the relatively greater thickness of the skin under the stringers would have a positive effect on the stiffness of the rivets in the skin, thereby compensating to some extent for the reduction of thickness in the chemimilled pockets. A representative Z-section stringer was chosen, and calculations made for various depths of chemimilling. The local buckling stress of the chemi-milled panel was expressed as a multiplication factor $F$ on the buckling stress of the same panel with a uniform skin thickness equal to the thickness of the chemi-milled pockets $\left(t_{\mathrm{b}}=t_{\mathrm{red}}\right.$ in Eq. 21). For incorporation into the spreadsheet, a quadratic function was found to provide a fit to the calculated data, given by the following formula:

$F=1+0.155\left(1-\frac{t_{\text {red }}}{t_{0}}\right)+1.309\left(1-\frac{t_{\text {red }}}{t_{0}}\right)^{2}$

within the range $0.25 \leq t_{\text {red }} / t_{0} \leq 1.0$ and based on a panel with $b_{\text {red }} / b=0.85$. Note that while the factor $F$ is greater than 1 , the net effect is, of course, a reduction in the local buckling stress as a result of chemi-milling. Nevertheless, Eq. (23) shows that the thickness of the unmilled skin under the stringers is effective in limiting the extent of this reduction. Further calculations have since been made for different ratios of width of chemi-milled pocket to stringer pitch $\left(b_{\text {red }} / b>0.85\right)$, showing gradually reducing values of the factor $F$ with increasing values of this ratio as expected. However, the effect of this on the optimised panels was judged to be quite small. The simplified approach adopted here for the buckling of the chemi-milled panels has been verified by a more detailed analysis of the panels, coming out of the different stages of optimisation. It was shown that the difference between the spreadsheet formulae (Eqs. 22 and 23) and the results of the program in ESDU Data Item 98016 (ESDU 1998) was less than 4\%, which is satisfactory for the present purpose.

For local buckling under combined compression and shear, the well known parabolic interaction formula is used. Buckling occurs when:

$\frac{\sigma}{\sigma_{\mathrm{L}}}+\left(\frac{\tau}{\tau_{\mathrm{B}}}\right)^{2}=1$

where $\sigma$ and $\tau$ are the applied compressive and shear stresses, respectively, and $\tau_{\mathrm{B}}$ is the buckling stress in pure shear:

$\tau_{\mathrm{B}}=K_{\mathrm{S}} E\left(\frac{t_{\mathrm{red}}}{\mathrm{b}}\right)^{2}$

where a representative value of the buckling coefficient is taken to be $K_{\mathrm{S}}=4.83$ (ESDU 1971a, Data Item 71005).

For the inter-rivet buckling stress $\sigma_{\mathrm{R}}$ the usual empirical formula (ESDU 1962, Data Item 02.01.08) is used:

$\sigma_{\mathrm{R}}=K_{\mathrm{R}} E\left(\frac{t_{0}}{r_{\mathrm{p}}}\right)^{2}$

in which $K_{\mathrm{R}}=1.23$ is taken for conventional countersunk rivets and $r_{\mathrm{p}}$ is the rivet pitch.

For the material stress limitation, an appropriate value of allowable stress is used when the panel is loaded under pure compression. Note that this is simply a cut-off value, i.e. at this stage no consideration is given to a reduction in the (tangent) modulus with the approach of yielding. The stress levels in this study are low enough to make use of a reduced modulus unnecessary. However, this is readily incorporated without departing from the intention of 
employing explicit formulae for all failure modes. Under combined compression and shear, the von Mises equivalent stress $\sigma_{\mathrm{VM}}$ is used:

$\sigma_{\mathrm{VM}}=\sqrt{\sigma^{2}+3 \tau^{2}}$

This is again related to the allowable compressive stress of the material.

\section{Optimisation}

The goal of the optimisation process is to link together the structural analysis and the cost analysis in order to define the design configuration that meets the structural requirements while minimizing the cost to the airline operator.

\subsection{Optimisation method}

The various formulae for cost estimation and structural analysis presented in the previous sections have been incorporated into a Microsoft "Excel" spreadsheet. The structural analysis simply ensures that the panel continues to withstand the load applied to it. Due to the explicit nature of both sets of formulae, effective use could be made of the "Solver" optimisation routine in Excel, which employs a generalized reduced gradient method. Formulae for the different modes of failure developed in the structural analysis serve as constraints in the optimisation (together with certain other constraints arising from the limits of validity of the local buckling data).

\subsection{Definition of the objective function}

There are various ways of driving the design process to be mindful of cost, but this is generally achieved through the formulation of a holistic objective function that is multidisciplinary in nature. In this context, the DOC as defined by Eq. (18) can be used as an objective function to reflect both manufacturing cost and weight penalty. It is supposed that a marginal saving in the DOC of the aircraft (i.e. saving directly attributable to the design of the panel) is made up of a saving in manufacturing cost offset against a fixed cost penalty for any increase in structure weight. However, pure profitability would be more accurate while possible consequences of changes in the design for durability or maintenance costs are not considered at the present stage. It is also assumed that any weight increase is marginal and does not imply reduction in performance of the aircraft. It should be noted that additional fuel costs are paid for over the life of the aircraft, whereas manufacturing costs are met at the outset.
For comparison purposes, a classical weight optimisation is also performed. A detailed analysis is then necessary to compute the weight of the panel, obtained by summing the weight of each part. For the panel, the actual geometry after chemi-milling is taken into account. The weight of the frames is calculated taking into account the actual size of the frames and removing the amount of material corresponding to the holes. The weight of the rivets is computed on the basis that the amount of material added due to the rivets (weight of the rivet minus the weight of the material removed for the hole) is $2 \mathrm{~g}$. This is a good approximation when considering the rivets used for this type of panel. The weight of the stringers is computed from their length and cross-sectional area.

A previous analysis of $\mathrm{T}$-stringer panels has shown that the choice of objective function is crucial (Curran et al. 2006). Very different results for the design parameters were obtained according to the objective function, and the minimum weight condition was found not to be the optimal solution from a minimum life cycle cost point of view.

\subsection{Application to a chemi-milled panel}

The present application concerns the optimisation of a Zstringer chemi-milled panel. The active design variables are chosen to be: stringer pitch $b$, stringer height $h$, initial sheet thickness $t_{0}$, thickness of the pockets after chemimilling $t_{\text {red }}$, stringer thickness $t_{\mathrm{s}}$ and rivet pitch $r_{\mathrm{p}}$. The last parameter is chosen because it makes a major contribution to the cost of manufacture while the other five parameters are primary variables in the design of a stringer-skin panel, as well as having significant influence on the manufacturing cost. An appropriate part of the frame and cleat weight is included in the total weight of the panel. The frame pitch $\left(L_{\mathrm{F}}=406 \mathrm{~mm}\right)$ is not varied during optimisation. For the present study the panel is loaded in compression and shear, at a structural index value $p / L_{\mathrm{f}}=0.5 \mathrm{~N} / \mathrm{mm}^{2}$, with $q=$ $p / 5$. For this application, a fixed cost penalty of $1.2 \times$ $10^{5}$ [unit currency $/ \mathrm{kg}$ ] has been adopted. A minimum value of $1.27 \mathrm{~mm}$ for $t_{0}$ is imposed as a constraint, representing the minimum skin thickness necessary for riveting.

To compute the number of frames, the panel length is simply divided by the frame pitch while dividing the panel width by the stringer pitch gives the number of stringers. It is assumed that there is one cleat at every frame-stringer junction. Ideally, these figures should be rounded to the closest integer value as the quantity of each type of part has to be represented by an integer. Nevertheless, the use of integers in combination with the "Solver" routine in Excel led to the appearance of local minima during the optimisation process. For this reason, the decision to keep unrounded numbers for this analysis has been made. The 
investigation of optimisation routines specially dedicated to accept integer variables will be considered in future applications. To ensure that the global minimum is found, optimisations starting with different initial values of the design parameters have been performed.

Table 2 shows the results of the optimisation for weight or DOC, with and without chemi-milling. Comparing the optimisation for weight and for DOC, it can be concluded that, as for the T-stringer panel application (Curran et al. 2006), there is an improvement in DOC for the minimum DOC condition over the minimum weight condition. This is due to the important manufacturing cost saving having a reduced number of larger-area stringers, a larger rivet pitch and a slightly thicker skin. Indeed, comparing the two last rows of Table 2 for example, it can be seen that the panel optimised for DOC has a stringer pitch almost tripled, a skin thickness doubled, and a stringer thickness and rivet pitch more than doubled compared to the panel optimised for weight. For this example, the manufacturing cost is reduced by $44 \%$ while the weight and fuel burn only increase by $29 \%$. Similar conclusions can be made comparing the two first rows of Table 2. Globally, the total cost improvement corresponds to $34 \%$ of the DOC for the chemi-milled panel and to $15 \%$ of the DOC for the panel without chemi-milling. It is emphasized that these percentages relate strictly to that part of the DOC directly attributable to the design of the fuselage panels, and do not relate to the total DOC of the aircraft.

Comparing the results with chemi-milling and without chemi-milling in Table 2, it can be concluded that the chemi-milling process is necessary to obtain the optimal panel, either when optimising for weight or for DOC, but optimisation for weight requires more chemi-milling than optimisation for DOC. Nevertheless, the improvement in DOC between the panel with chemi-milling and the panel without chemi-milling, in both cases optimised for DOC, is only $1.5 \%$ and this value is very sensitive to the fuel cost. This statement means that chemi-milled panels do not show a substantial advantage on a DOC basis when only static strength (material allowable stresses and buckling) is taken into account. In practice, the advantage is likely to be more discernible in their crack-stopping properties in fatigue resulting from repeated cabin pressurization. It can also be concluded from rows two and four in Table 2 that with no increase in DOC, the chemi-milling process can make the fuel burn go down, the aircraft being more environmentally efficient. Indeed, looking at the panels optimised for DOC, the chemi-milled panel is $7 \%$ lighter than the panel without chemi-milling, the slight increase in manufacturing cost being compensated by the reduction in fuel burn.

The assumption on which Eq. (23) is based $\left(b_{\text {red }} / b=0.85\right)$ is correct when optimising for weight but not when optimising for DOC, for which the value should be 0.95 . As stated above, an improved formula for local buckling, including the effect of the $b_{\text {red }} / b$ ratio, has been developed. The maximum difference between the two formulae being only $0.2 \%$, it has been decided to retain Eq. (23) in the spreadsheet.

\section{Conclusion}

The main finding of the paper is that optimising the design according to DOC rather than structural weight can result in reduced manufacturing costs that lower the aircraft DOC despite the extra cost incurred when the fuel burn penalty is taken into account. An original technique for modelling manufacturing cost using the genetic-causal approach has been used to facilitate the optimisation process and the impact of including manufacturing considerations has been highlighted in comparative results. It has been shown that an effective design optimisation can been achieved by linking manufacturing costs models with structural analysis models through shared design parameters.

Structurally improved buckling coefficients to account for the actual geometry of the panel in case of chemimilling have been defined. When analysing the impact of chemi-milling, it has been shown that the thickness to be removed by chemi-milling is less when optimising for minimum DOC rather than for minimum weight and that, even if this process increases the total manufacturing cost, chemi-milling has a slightly favourable impact on the total DOC compared to a configuration without chemi-milling when optimised for DOC.

Table 2 Design parameters and cost results after optimisation

\begin{tabular}{|c|c|c|c|c|c|c|c|c|c|c|c|c|c|}
\hline Optimised for & & $\begin{array}{l}b \\
(\mathrm{~mm})\end{array}$ & $\begin{array}{l}h \\
(\mathrm{~mm})\end{array}$ & $\frac{b_{\mathrm{red}}}{b}$ & $\begin{array}{l}t_{0} \\
(\mathrm{~mm})\end{array}$ & $\begin{array}{l}t_{\mathrm{red}} \\
(\mathrm{mm})\end{array}$ & $\begin{array}{l}t_{0}-t_{\text {red }} \\
(\mathrm{mm})\end{array}$ & $\begin{array}{l}t_{\mathrm{s}} \\
(\mathrm{mm})\end{array}$ & $\begin{array}{l}r_{\mathrm{p}} \\
(\mathrm{mm})\end{array}$ & $\begin{array}{l}\mathrm{W} \\
\left(\mathrm{kg} / \mathrm{m}^{2}\right)\end{array}$ & $\begin{array}{l}\text { DOC } \\
\text { (unit } \\
\text { currency/m²) }\end{array}$ & $\begin{array}{l}\text { FB } \\
\text { (unit } \\
\text { currency } / \mathrm{m}^{2} \text { ) }\end{array}$ & $\begin{array}{l}\text { MFC } \\
\text { (unit } \\
\text { currency } / \mathrm{m}^{2} \text { ) }\end{array}$ \\
\hline \multirow{2}{*}{$\begin{array}{l}\text { With } \\
\text { chemi-milling }\end{array}$} & W & 57.15 & 18.93 & 0.83 & 2.71 & 1.26 & 1.45 & 1.01 & 57.98 & 8.539 & $2908.7 \times 10^{3}$ & $1024.7 \times 10^{3}$ & $376.8 \times 10^{3}$ \\
\hline & DOC & 155.79 & 14.44 & 0.95 & 3.81 & 2.57 & 1.24 & 3.98 & 101.97 & 10.757 & $2168.3 \times 10^{3}$ & $1290.8 \times 10^{3}$ & $175.5 \times 10^{3}$ \\
\hline \multirow{2}{*}{$\begin{array}{l}\text { Without } \\
\text { chemi-milling }\end{array}$} & W & 63.58 & 19.03 & - & 1.56 & 1.56 & 0 & 1.25 & 34.46 & 8.909 & $2528.6 \times 10^{3}$ & $1069.1 \times 10^{3}$ & $291.9 \times 10^{3}$ \\
\hline & DOC & 173.37 & 17.05 & - & 3.05 & 3.05 & 0 & 3.32 & 85.80 & 11.483 & $2201.5 \times 10^{3}$ & $1378.0 \times 10^{3}$ & $164.7 \times 10^{3}$ \\
\hline
\end{tabular}


The work presented is part of research in progress whose further developments will include the analysis of manufacturing and material alternatives in order to trade-off the cost implications for acquisition cost and maintenance.

Acknowledgments The work has been carried out through the Centre of Excellence for Integrated Aircraft Technology (CEIAT), funded by Invest Northern Ireland and Bombardier Aerospace Belfast (BAB). The authors would like to acknowledge the strong collaboration with $\mathrm{BAB}$, involving the gathering of industrial data and the ultimate relevance of the work. In particular, thanks go to Stephen Cowan and Paddy Hawthorne in Procurement, Martin Bishop and Tamera Dalton in Methods, Mark White and Joe Lowry in Design, and David Nelson in the Fabrications Division.

\section{References}

Asiedu Y, Gu P (1998) Product life cycle cost analysis: state of the art review. Int J Prod Res 36:883-908

ASM (1988) The Materials Information Society. Conventional hot extrusion. Metals handbook, vol 14. Forming and forging. ASM International, Ohio, pp 315-326

ASM (1990) The Materials Information Society. Aluminum mill and engineered wrought products. Metals handbook, vol 2. Properties and selection: non-ferrous alloys and special-purpose materials. ASM International, Ohio, pp 30-61

Bao HP, Samareh JA (2000) Affordable design: a methodology to implement process-based manufacturing cost models into the traditional performance-focused multidisciplinary design. AIAA/ NASA/USAF/ISSMO Multidisciplinary analysis and optimisation symposium, AIAA, Long Beach, September 2000

Ben-Arieh D, Qian L (2003) Activity-based cost management for design and development stage. Int J Prod Econ 83:169-183

Collopy P, Horton R (2002) Value modeling for technology evaluation. AIAA/ASME/SAE/ASEE Joint propulsion conference and Exhibit, AIAA, Indianapolis, July 2002

Curran R, Kundu A, Raghunathan S, Eakin D, McFadden R (2003) Influence of manufacturing tolerance on aircraft direct operating cost (DOC). J Mat Proc Tech 138:208-213
Curran R, Rothwell A, Castagne S (2006) Numerical method for costweight optimisation of stringer-skin panels. J Aircraft 43:264274

Dean EB (1995) Parametric cost deployment. In: Proceedings of the 7 th symposium on quality function deployment, Novi, MI, pp $27-34$

Engineering Sciences Data Unit (1962) Buckling in compression of sheet between rivets. Data Item 02.01.08, structures series, ESDU, London

Engineering Sciences Data Unit (1971a) Buckling of plates in shear. Data Item 71005, structures series, ESDU, London

Engineering Sciences Data Unit (1971b) Local buckling of compression panels with flanged stringers. Data Item 71014, Structures series, ESDU, London

Engineering Sciences Data Unit (1998) Elastic buckling of flat isotropic stiffened panels and struts in compression. Data Item 98016, structures series, ESDU, London

Feng SC, Song EY (2003) A manufacturing process information model for design and process planning integration. J Manuf Syst 22:1-15

Kassapoglou C (1999) Minimum cost and weight design of fuselage frames. Part B: Cost considerations, optimisation and results. Composites Part A 30:895-904

Koonce D, Judd R, Sormaz D, Masel DT (2003) A hierarchical cost estimation tool. Comput Ind 50:293-302

Marx WJ, Mavris DN, Schrage DP (1995) A hierarchical aircraft life cycle cost analysis model. AIAA Aircraft Engineering, Technology, and Operations Congress, AIAA, Anaheim, September, 1995

Pantelakis SG, Baxevani EA (2002) Optimization of the diaphragm forming process with regards to product quality and cost. Composites Part A 33:459-470

Rigo P (2003) An integrated software for scantling optimization and least production cost. Ship Technol Res 50:126-141

Roy R, Bendall D, Taylor JP, Jones P, Madariaga AP, Crossland J, Hamel J, Taylor IM (1999) Development of airframe engineering CER's for aerostructures. Proceedings of the Second World Manufacturing Congress (WMC'99), Durham (UK), pp 838-844

Wang K, Kelly D, Dutton S (2002) Multi-objective optimisation of composite aerospace structures. Composites Struct 57:141-148

Weustink IF, ten Brinke E, Streppel AH, Hals HJJ (2000) A generic framework for cost estimation and cost control in product design. J Mater Proc Tech 103:141-148 